\title{
SOBREVIVÊNCIA DE LEGUMINOSAS ARBUSTIVAS EM PASTAGEM CONSORCIADA, ITUPIRANGA, PA
}

\author{
Fabrício Marinho Lisbôa ${ }^{1}$; Alzira Gabriela da Silva Pause ${ }^{2}$ \\ ${ }^{1}$ Discente do curso de Agronomia, Faculdade de Ciências Agrárias de Marabá (FCAM), Universidade Federal do Pará \\ (UFPA), fabriciomarinho87@yahoo.com \\ ${ }^{2}$ Prof., D.Sc., FCAM, UFPA, alziragabi@ufpa.br
}

\begin{abstract}
RESUMO: No sudeste paraense uma das principais atividades econômicas é a pecuária. Esta atividade apóia-se sobre extensas áreas de pastagem que, em sua maioria, encontra-se em algum estágio de degradação. Com o propósito de otimizar o sistema solo-planta, objetivou-se verificar a percentagem de mudas de leguminosas arbustivas implantadas em área de pastagem já estabelecida de Brachiaria brizantha (Hochst ex A. Rich.) Stapf. Os tratamentos foram pastagem de Brachiaria brizantha e Cajanus cajan (PBCC); Brachiaria brizantha e Crotalaria juncea (PBCJ) com quatro repetições, sendo o delineamento inteiramente casualizado. Foram preparadas 32 mudas de cada espécie de leguminosa, das quais 8 mudas de Cajanus cajan foram plantadas em cada parcela de PBCC e 8 mudas de Crotalaria juncea em cada parcela de PBCJ. As mudas foram implantadas na área experimental no início do período chuvoso e a avaliação quantitativa foi realizada ao seu final. A sobrevivência das mudas revelou-se satisfatória, com maior percentagem de sobrevivência para Cajanus cajan.
\end{abstract}

PALAVRAS-CHAVE: Cajanus cajan, Crotalaria juncea, fixação biológica de nitrogênio, sudeste paraense.

\section{SUPERVIVÊNCIA DE LEGUMINOSAS ARBUSTIVAS EN PASTURAS CONSORCIADAS, ITUPIRANGA, PA}

RESUMEN: En el sudeste de Pará una actividad económica importante es la ganadería. Esta actividad se basa en extensas áreas de pastizales, en su mayoría se encuentran en alguna etapa de degradación. Con el objetivo de optimizar el sistema suelo-planta el objetivo de verificar el porcentaje de plantas arbustivas leguminosas en pasturas implantadas ya establecidos Brachiaria brizantha (Hochst ex A. Rich.) Stapf. Los tratamientos fueron: Brachiaria brizantha y Cajanus cajan (PBCC), B. brizantha y Crotalaria juncea (PBCJ) con cuatro repeticiones en un diseño completamente al azar. Hemos preparado 32 plántulas de cada especie leguminosa, incluyendo 8 de las plántulas de Cajanus cajan se sembraron en cada parcela de PBCC y 8 plantas Crotalaria juncea en cada parcela de PBCJ. Las plántulas fueron sembradas en el área experimental a principios de la temporada de lluvias y la evaluación cuantitativa se realizó al final. La supervivencia de las plántulas ha resultado satisfactorio, con la más alta tasa de supervivencia de Cajanus cajan.

PALABRAS CLAVES: Cajanus cajan, Crotalaria juncea, fijación biológica de nitrógeno, sudeste paraense. 


\section{INTRODUÇÃO}

No sudeste do Pará, uma das atividades de maior importância para a economia da região é a pecuária extensiva ou semiintensiva, prática que se apóia sobre extensas áreas de pastagens que em sua maioria encontram-se em algum estágio de degradação. Porém, apesar de serem a base para a pecuária nacional, as áreas pastoris têm experimentado rápido e acentuado declínio em sua capacidade produtiva em decorrência dos processos de degradação que se instalam, o que limita ou inviabiliza a atividade criatória (RODRIGUES et al., 2000).

Por não haver uma cobertura suficientemente capaz de proteger o solo, pastagens degradadas também afetam a qualidade do mesmo, uma vez que a erosão eólica e hídrica, além de outros, levam à redução da disponibilidade de nutrientes nesse solo (LEPSCH, 2002). Sendo assim, faz-se necessário a reposição de nutrientes para recuperação dessas áreas, o que pode ser obtido através do uso de leguminosas como alternativa de adubação orgânica, visto que, são capazes de fazer associações simbióticas com bactérias do gênero Rhizobium que fixam nitrogênio $(\mathrm{N})$ atmosférico e transferem à planta, ação essa que os vegetais não conseguem realizar sozinhos.

Esse $\mathrm{N}$ fica disponível tanto para a leguminosa quanto no solo, sendo assimilado por outros vegetais, o que pode trazer benefícios para a pastagem devido à transferência de $\mathrm{N}$ para as gramíneas (SALMAN, 2005). Esta é uma tecnologia de baixo custo e viável para agricultores familiares, pois, promove a melhoria do sistema solo-planta através do aporte de matéria orgânica e adição de $\mathrm{N}$ através da reciclagem de nutrientes sem, portanto, gastos com fertilizantes químicos.

No âmbito dessa questão, objetivou-se com esse estudo verificar o percentual de sobrevivência de leguminosas arbustivas em consórcio com pastagem Brachiaria brizantha (Hochst ex A. Rich.) Stapf. no período chuvoso em propriedade rural no município de Itupiranga, PA.

\section{MATERIAL E MÉTODOS}

Conduziu-se experimento na propriedade Três Irmãos, situada no km 90 da rodovia BR 230, Itupiranga - Pará, pontuado geograficamente pelas coordenadas $05^{\circ} 08^{\prime}$ $20^{\prime \prime}$ S e $49^{\circ} 19^{\prime} 25^{\prime \prime} \mathrm{W}$. O clima regional é do tipo Am no limite de transição para Aw com temperatura média anual de $26,35^{\circ} \mathrm{C}$, caracterizado por um período menos chuvoso entre os meses de maio a outubro e um período mais chuvoso entre os meses de novembro a abril (KOPPEN, 1948).

A propriedade está situada às margens da Rodovia Transamazônica, onde o desmatamento da floresta para a formação de áreas de pastagens e a extração ilegal de madeira, ainda é uma prática frequente. 
Portanto, o levantamento foi realizado nessa propriedade em função do acesso facilitado e da flexibilidade do proprietário em colaborar com a pesquisa.

As duas espécies arbustivas de leguminosas: Cajanus cajan (L.) Millsp. Sin. (Feijão-Guandú) e Crotalaria juncea L (Crotalária) foram introduzidas em pastagem de Brachiaria brizantha (Hochst ex A. Rich.) Stapf. implantada em 1993 via a prática de corte e queima.

Os tratamentos foram pastagem de Brachiaria brizantha e Cajanus cajan (PBCC); Brachiaria brizantha e Crotalaria juncea (PBCJ) com quatro repetições, sendo o delineamento inteiramente casualizado. Foram preparadas 32 mudas de cada espécie de leguminosa, no total de 64 , onde 8 mudas de Feijão-Guandú foram plantadas em cada parcela de PBCC e 8 mudas de Crotalária em cada parcela de PBCJ.

As mudas foram implantadas na área experimental em 19 de dezembro de 2009 e a avaliação quantitativa foi realizada seis meses após o plantio, ou seja, no final do período chuvoso. Para o cálculo de sobrevivência fezse uma regra de três simples, em que se contabilizou o número de mudas que foram plantadas e o número de mudas que sobreviveram expressos em percentagem.

\section{RESULTADO E DISCUSSÃO}

Ao final do período chuvoso realizou-se a contagem das mudas e detectou-se que $72 \%$ das mudas de Feijão-Guandú e 65,5\% de Crotalária sobreviveram (Figura 1).

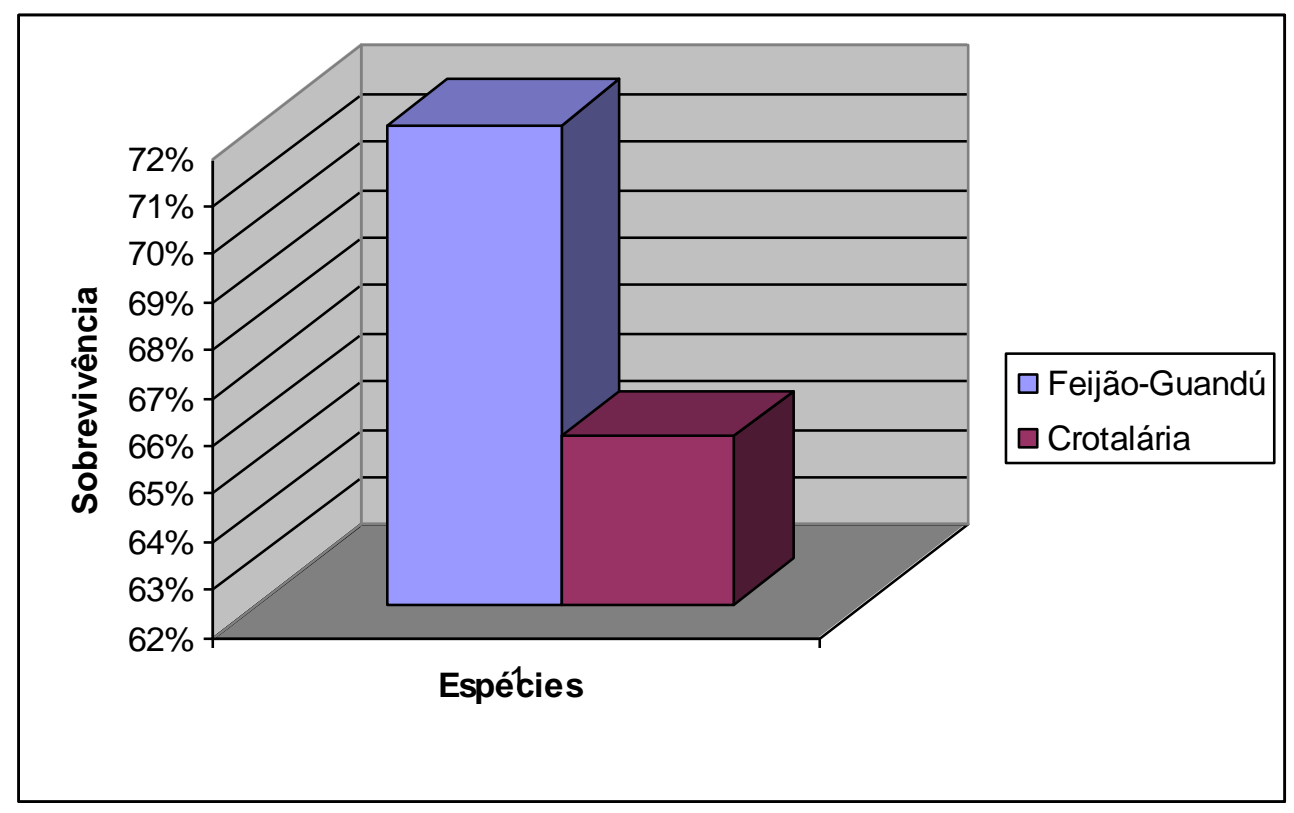

Figura 1. Sobrevivência a campo de mudas de leguminosas arbustivas.

Fonte: Dados de campo. 
A mortalidade das mudas provavelmente foi ocasionada pelo baixo $\mathrm{pH}$ do solo da área que, em média, apresentou valor de 5,2, portanto, considerado muito ácido (EMPRESA BRASILEIRA DE PESQUISA AGROPECUÁRIA, 1997). Outra causa pode ter sido a falta de nutrientes na solução do solo, agravado pelo fato da pastagem já estabelecida, nunca ter recebido reposição de nutrientes e pela adaptação das espécies à região de estudo.

A acidez do solo para leguminosas é um fator importante devido à associação com as bactérias fixadoras de nitrogênio, na associação Rhizobium - leguminosa o microssimbionte é o integrante da associação mais afetado pelo $\mathrm{pH}$ baixo dos solos (FERNANDES JÚNIOR; REIS, 2008). Segundo Seiffert e Thiago (1983) embora aceite $\mathrm{pH}$ de solo com variação entre 5 a 8 , o Feijão-Guandú apresenta melhor desempenho em solos aproximadamente neutros, o que evidencia assim, o grande desempenho desta leguminosa, a qual obteve $72 \%$ de sobrevivência no solo muito ácido da área experimental. A Crotalária também é uma espécie que se desenvolve em solos com $\mathrm{pH}$ que varia de 5 a 8,4; no entanto, assim como o Feijão-Guandú, desenvolve-se melhor em faixas de $\mathrm{pH}$ próximo ao neutro (CHAUDHURY et al., 1978).

A quantidade de nutrientes presentes no solo também é fator importante para a persistência das leguminosas. Segundo
Chaudhury et al., (1978), a nutrição mineral das leguminosas está diretamente relacionada com a nutrição mineral de Rhizobium, uma vez que maiores populações de Rhizobium tem sido encontradas em solos adubados, podendo-se aplicar fertilizantes para um incremento inicial da cultura. Para a cultura de Feijão-Guandú, o emprego de superfosfato simples granulado oferece diversas vantagens. Além de serem supridas as deficiências de fósforo e enxofre, este adubo granulado funciona como veículo para se distribuírem uniformemente os micronutrientes molibdênio, cobre e zinco, existentes no FTEBr 16, que é comercializado na forma e pó (SEIFFERT; THIAGO, 1983). Já para a Crotalária é recomendado a aplicação de adubo orgânico (3 a 5 t.ha $^{-1}$ ) no momento de preparação da terra, pois a matéria orgânica fornece carbono e fonte de energia aos Rhizobium; ou de 5 a $10 \mathrm{~kg} \cdot \mathrm{ha}^{-1}$ de N, pois apesar de ser uma leguminosa, a Crotalária não tem em sua composição todo o nitrogênio que necessita (CHAUDHURY et al., 1978).

Em relação à adaptação às condições edafoclimáticas, o Feijão-Guandú tem-se destacado no Brasil, entre outras leguminosas forrageiras, em função de sua notável tolerância à seca e adaptação aos solos pouco férteis, com grande potencial de produção de fitomassa, mesmo em períodos de estiagem (WUTKE, 1987). Enquanto que, a Crotalária sobrevive tanto em regiões de clima tropical e sub-tropical, no Brasil, a cultura é cultivada 
na região Amazônica onde pode não ser favorecida pela quantidade de luz do fotoperíodo, uma vez que é uma planta de dias curtos (CHAUDHURY et al., 1978; BULISANI et al., 1980).

\section{CONCLUSÕES}

Com o exposto pôde-se concluir que leguminosas estudadas podem ser utilizadas para programas de recuperação de pastagens e solos degradados, devido à taxa de sobrevivência considerada satisfatória, com especial atenção para o Feijão-Guandú. Novos experimentos devem ser realizados com o propósito de estudar e conhecer o comportamento destas espécies na região.

\section{REFERÊNCIAS}

BULISANI, E. A. et al. Épocas e espaçamento de semeadura em Crotalaria juncea L. Bragantia, Campinas, vol. 39, n. 16, p. 237-240, out. 1980. Disponível em:< http://www.scielo.br/pdf/brag/v39n1/31.pdf >. Acesso em: 19 set. 2010.

CHAUDHURY, J.; SINGH, D. P.; HAZRA, S. K.; Sunnhemp (Crotalaria juncea, L.). CENTRAL RESEARCH INSTITUTE FOR JUTE \& ALLIED FIBRES (ICAR). 1978. Disponível em: $<$ http://assamagribusiness.nic. in/Sunnhemp.pdf>. Acesso em: 19 set. 2010.

EMPRESA BRASILEIRA DE PESQUISA AGROPECUÁRIA. Manual de métodos de análise de solo. 2. ed. EMBRAPA, Rio de Janeiro, 1997. 212p.

FERNANDES JÚNIOR P. I.; REIS, V. M. Algumas limitações à fixação biológica de nitrogênio em leguminosas. EMBRAPA Agrobiologia, 2008. 33p. (Documentos 252).
Disponível em: $<$ http://www.cnpab. embrapa.br/publicacoes/download/doc252.pdf >. Acesso em: 19 set. 2010.

KOEPPEN, W. Climatologia Tradicional.Traduzido para o Espanhol por Pedro Henchiehs Pérez, 1948.

LEPSCH, I. F. Formação e Conservação do Solo. São Paulo: Oficina de Textos, 2002.

RODIRGUES, L. R. A.; QUADROS, D. G.; RAMOS, A. K. B. Recuperação de Pastagens Degradas. In: SIMPÓSIO PECUÁRIA 2000: PERSPECTIVAS PARA O III MILÊNIO, 1. 2000, Pirassununga. Anais.. Pirassununga: FZEAUSP, 2000. Disponível em:< $\mathrm{http} / /$ www.neppa.uneb.br/textos/publicacoes/simposios/r ecuperacao_pastagens.pdf $>$. Acessoem: 19 set. 2010.

SALMAN, A. K. D. Consorciação de gramíneas e leguminosas forrageiras em pastagens na Amazônia. 2005. Disponível em: http://www.cpafro.embrapa.br/embrapa/Artigos/ gram ideslegu.htm. Acesso em: 3 jun. 2010

SEIFFERT, N. F.; THIAGO L. R. L. S. Guandu - planta forrageira para a produção de proteína. EMBRAPA - Gado de Corte, nov. 1983. (Comunicado Técnico ${ }^{\circ}$ 21). Disponível em: $<$ http://www.cnpgc. embrapa.br/publicacoes/cot/COT21.html . Acesso em: 19 set. 2010.

WUTKE, E. B. Caracterização fenológica e avaliação agronômica de genótipos de guandu[(Cajanus cajan (L.) Millsp.)]. Piracicaba. 1987. 164 f. Dissertação (Mestrado em Fitotecnia) - ESALQ/USP, Piracicaba, SP, 1987.

\section{AGRADECIMENTOS}

O presente trabalho foi realizado com o apoio da Pró - Reitoria de Extensão da Universidade Federal do Pará (PROEX). 